Journal of Animal and Veterinary Advances 11 (19): 3539-3543, 2012

ISSN: $1680-5593$

(C) Medwell Journals, 2012

\title{
Distribution and Habitat Conditions of Habitat Points of the Eurasian Otter Lutra lutra in the Hangang River Water System, South Korea
}

\author{
${ }^{1,2}$ Jung-Hoon Kang and ${ }^{1}$ Shin-Jae Rhim \\ ${ }^{1}$ School of Bioresource and Bioscience, Chung-Ang University, 456-756 Ansung, Korea \\ ${ }^{2}$ Natural Heritage Center, Cultural Heritage Administration, 302-834 Daejeon, Korea
}

\begin{abstract}
Researchers conducted this study to clarify the distribution and habitat conditions of the Eurasian otter Lutra lutra in the Hangang water system, South Korea. Researchers evaluated a total 358 habitat sites widely distributed in the Hangang river water system. The altitudinal distribution ranges were similar in the Bukhangang and Namhangang areas. The width of river in habitat points ranged from 4-1,017 $\mathrm{m}$. The mean water velocity was $0.32 \pm 0.15 \mathrm{~m} \mathrm{sec}^{-1}$. Habitat variables such as site condition, river width, bottom status, bankside vegetation, land use type, grass height, vegetation cover, artificial structures, water use and pollutants were significantly different among areas except for forest type and shrub height. Furthermore, land use type, artificial structures, water use and pollutants were disturbance factors. To conserve the Eurasian otter and its habitat, the riparian habitat should be managed and conserved.
\end{abstract}

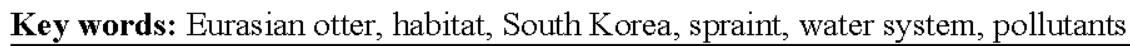

\section{INTRODUCTION}

Human activities in riparian ecosystems such as dam construction, housing, cultivation and road construction, have increased dramatically over the past 50 years in South Korea. This has led to dramatic changes in riparian habitats, fish populations and the structure of biological communities across the entire water system as well as a reduction in water quality, flow rate and temperature. Furthermore, artificial structures (e.g., dam walls) prevent the natural movement and migration of fish and other species (Alam et al., 1995; Collares-Perira et al., 2000; Sales-Luis et al., 2007).

The population of the Eurasian otter Lutra lutra has decreased dramatically in the Palearctic (Macdonald et al., 1994). This mammal is now rare or extinct in many Eurasian countries. Several researchers have investigated the habitat and environmental factors that affect the Eurasian otter (Lunnon and Reynolds, 1991; Prenda and Granadio-Lorencio, 1996). Aside from factors such as dense riparian cover and low disturbance, good habitat for Eurasian otters should include foraging areas with abundant food resources (Beja, 1996). The minimum habitat requirements of mammals, however are still not fully understood.

Human disturbance, habitat destruction caused by drainage schemes, an increase in water pollution, drowning in fish traps and traffic accidents are thought to have contributed to the decline in abundance of the Eurasian otter (Macdonald et al., 1994; Madsen and Prang, 2001). Although, human activities have been implicated in the decline of this species in South Korea (Han, 1987), the effect of human activities upon the distribution and habitat of otters are still largely unknown. The Eurasian otters are very shy and difficult to observe directly in their natural habitat (Jefferies, 1987). Otters are inherently difficult to study because as top predators, they are found at relatively low densities even under optimal conditions and they have a semi-aquatic life-style (Robitaille and Laurence, 2002). For these reasons, the numbers and distribution of spraints are often used to assess otter population status, activity and habitat preference (Kruuk and Conroy, 1987), although many researchers have urged that this technique be used with caution when trying to assess abundance and habitat use (Jefferies, 1986; Mason and Macdonald, 1987; Prigioni et al., 2006).

The Eurasian otter is listed as No. 330 in natural monument and endangered species in South Korea. To manage and conserve the Eurasian otters, it is critical to understand the habitat components that are important for this mammal. The purpose in this study was to examine the distribution and relative influence of habitat conditions on the Eurasian otter in the Hangang river water system, South Korea.

Corresponding Author: Shin-Jae Rhim, School of Bioresource and Bioscience, Chung-Ang University, 456-756 Ansung, Korea 


\section{MATERIALS AND METHODS}

Researchers conducted this study along the Hangang river water system $\left(37^{\circ} 21^{\prime} \mathrm{N}, 128^{\circ} 00 \mathrm{E}\right)$, South Korea (Fig. 1). The size of the Hangang river water system is $25,954 \mathrm{~km}^{2}$ and its total length is $494 \mathrm{~km}$ (KWRC, 2002). The Hangang river water system is $27 \%$ of the size of South Korea. It is a very important water resource for Seoul, the capital of South Korea. Due to urbanization and civilization of Seoul and its vicinity, the pressure to further develop and exploit the Hangang River water system is increasing (SMG, 2002). The Hangang water system can be divided into the Bukhangang and Namhangang areas. Researchers investigated sites in Gyeonggi, Gangwon and North Chungcheong provinces.

Researchers conducted field surveys from April 2009 to October 2011. Only spraints or footprints were accepted as evidence of Eurasian otter (Madsen and Prang, 2001). Field signs of the Eurasian otter were surveyed and collected by boat and on foot in the

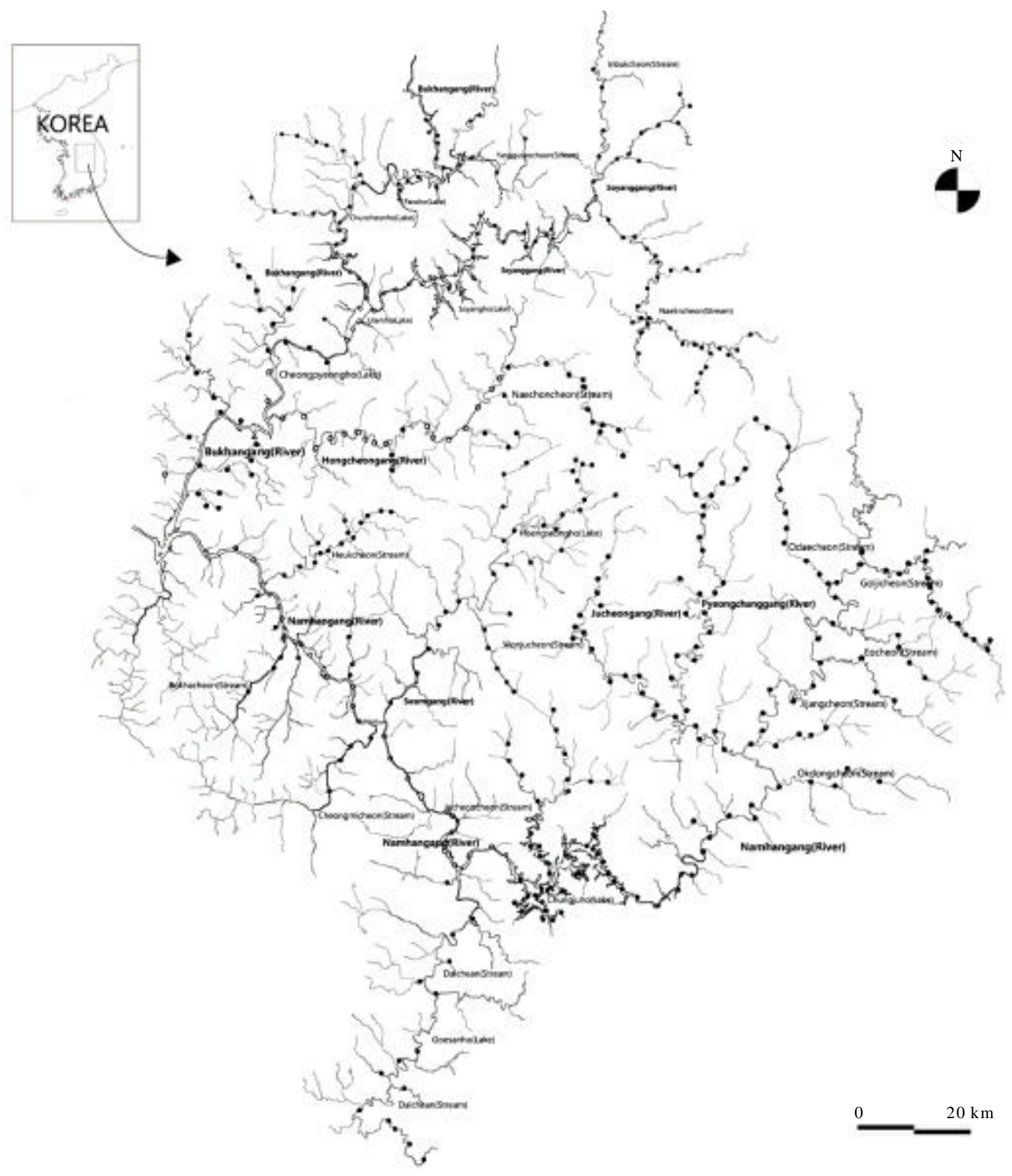

Fig. 1: Distribution of habitat points $(\bullet)$ of the Eurasian otter Lutra lutra in the Bukhangang and Namhangang regions of the Hangang river water system, South Korea 
Table 1: Description of habitat variables of the Eurasian otter Lutra lutra in

\begin{tabular}{ll}
\multicolumn{2}{c}{ this study (Madsen and Prang, 2001) } \\
\hline Variables & Description \\
\hline Altitude & masl \\
River width & $\mathrm{m}$ \\
Water velocity & $\mathrm{m} \mathrm{sec}^{-1}$ \\
Site conditions & River, confluence, reservoir and dam \\
River depth & $\mathrm{m}$ \\
Bottom status & Sand, gravel, bedrock and rock \\
Bankside vegetation & Herbs, shrubs, trees and none \\
Land use type & Uncultivated, cultivated, fallow, residential \\
Forest type & Coniferous, deciduous, mixed and none \\
Grass height & $30-60,60-90,90-120$ and $>120 \mathrm{~cm}$ \\
Shrub height & $1.0-1.5,1.5-2.0,>2.0 \mathrm{~m}$, absent \\
Land cover & $1-33 \%, 34-66 \%, 67-100 \%$ \\
Artificial structures & Bank revetment, sluice gates under bridge, pier, \\
& houses and none \\
Water use & Agricultural, watersports, fishing and conservational \\
Pollutants & Non polluted, farming, living and industrial \\
\hline
\end{tabular}

Bukhangang and Namhangang areas of the Hangang river water system. If spraints or footprints of the Eurasian otter were observed, researchers recorded that site as a habitat point using a Global Positioning System (GPS) unit.

Data for 15 variables were collected to determine the habitat conditions (Table 1). For all habitat points and randomly selected non-observed points (control), researchers created a quadrat $(100 \times 100 \mathrm{~m})$. Within this quadrat, researchers surveyed physical features (site conditions, river depth, bottom status and bankside vegetation), status of the adjacent area (land use type, forest type, grass height, shrub height and vegetation cover) and disturbance factors (artificial structures, water use and pollutants) during August and September, 2011. The variables chosen are primarily related to the nature of the water course, cover and levels of human disturbance.

Researchers performed frequency analysis of the habitat variables to clarify the habitat preferences of the Eurasian otter in the Hangang river water system. The data were analyzed using the t-test, Analysis of Variance (ANOVA) and Pearson $\chi^{2}$-test. The Dunnett T3 test was used in post-hoc comparisons of mean values. The p-values are reported.

\section{RESULTS}

Researchers recorded a total 358 habitat points for the Eurasian otter (130 sites in Bukhangang and 228 sites in Namhangang) in the Hangang river water system, South Korea during the study period. The habitat points of the Eurasian otter were widely and evenly distributed in the Hangang river water system (Fig. 1).

The altitudinal distributions of the habitat points ranged from 31-678 masl. The altitudinal distribution ranges were similar in the Bukhangang and Namhangang areas. The mean altitude was $267.04 \pm 12.37 \mathrm{~m}$ (mean $\pm \mathrm{SE}$ ) in
Table 2: Frequency of habitat points of the Eurasian otter Lutra lutra according to altitude (masl) in Bukhangang, Namhangang and control areas of the Hangang river water system, South Korea

\begin{tabular}{lccc}
\hline Altitude $(\mathrm{m})$ & $\begin{array}{c}\text { Bukhangang } \\
(\mathrm{n}=130)\end{array}$ & $\begin{array}{c}\text { Namhangang } \\
(\mathrm{n}=228)\end{array}$ & $\begin{array}{c}\text { Control } \\
(\mathrm{n}=71)\end{array}$ \\
\hline $0-100$ & 9 & 32 & 45 \\
$101-200$ & 42 & 74 & 25 \\
$201-300$ & 30 & 45 & 1 \\
$301-400$ & 26 & 30 & - \\
$401-500$ & 12 & 23 & - \\
$501-600$ & 9 & 15 & - \\
$601-700$ & 2 & 9 & - \\
\hline
\end{tabular}

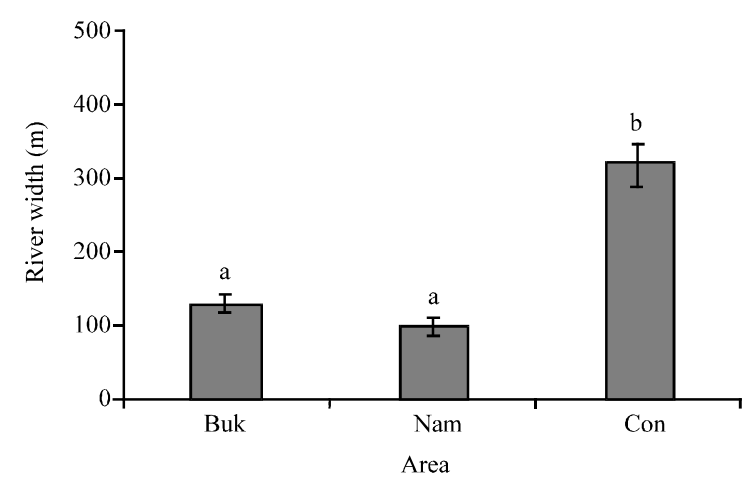

Fig. 2: Difference in river width (m) of the habitat points of Eurasian otter Lutra lutra as determined by ANOVA in Bukhangang (Buk), Namhangang (Nam) and Control areas (Con) of the Hangang River water system, South Korea. Different letters indicate significant differences between the mean values $(\mathrm{p}<0.05)$

Bukhangang and $256.79 \pm 10.91 \mathrm{~m}$ in Namhangang. There was no significant difference in the mean altitude of habitat points between Bukhangang and Namhangang (t-test, $\mathrm{t}=0.62, \mathrm{p}=0.54$ ) (Table 2).

The width of river ranged from 4-1,017 masl. In Bukhangang, river ranged in width from $5-740 \mathrm{~m}$ with a mean width of $124.86 \pm 14.56 \mathrm{~m}$ whereas in Namhangang, the river ranged in width from $4-1,017 \mathrm{~m}$ with a mean width of $99.65 \pm 9.37 \mathrm{~m}$. In the control areas, the river ranged in width from $5-845 \mathrm{~m}$ with a mean width of $320.14 \pm 25.42 \mathrm{~m}$. The mean of river widths were significantly different among areas (ANOVA, $F=50.85, \mathrm{p}<0.01$ ). When Bukhangang and Namhangang were grouped into one group and compared with the control, the mean river width was significantly different between this group and the control (Dunnett T3 test, $\mathrm{p}<0.01$ ) (Fig. 2).

Water velocity in the habitat points ranged from $0.0-1.7 \mathrm{~m} \mathrm{sec}^{-1}$ with a mean of $0.32 \pm 0.15 \mathrm{~m} \mathrm{sec}^{-1}$. Water velocities were significantly different among areas $(\mathrm{F}=24.76, \mathrm{p}<0.01)$. The mean water velocity of control sites was different from that of habitat points in 


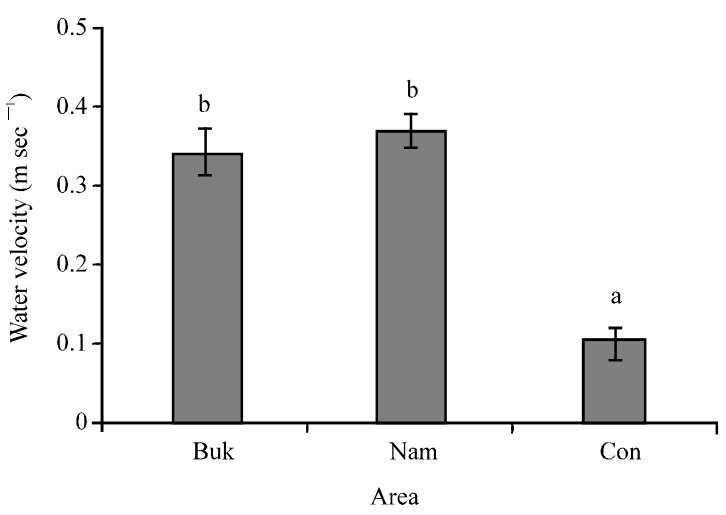

Fig. 3: Difference in water velocity $\left(\mathrm{m} \mathrm{sec}^{-1}\right)$ of habitat points of Eurasian otter Lutra lutra as determined by ANOVA in Bukhangang (Buk), Namhangang (Nam) and Control areas (Con) of the Hangang River water system, South Korea. Different letters indicate significant differences between the mean values $(\mathrm{p}<0.05)$

Table 3: Pearson $\chi^{2}$-test result of cross-analysis of habitat conditions for spraint points of the Eurasian otter Lutra lutra in the Hangang river water system, South Korea

\begin{tabular}{lccl}
\hline Variables & df & $\chi^{2}$ & p-value \\
\hline Site conditions & 6 & 26.20 & $<0.01$ \\
Stream depth & 6 & 60.98 & $<0.01$ \\
Bottom status & 6 & 48.15 & $<0.01$ \\
Bankside vegetation & 6 & 89.27 & $<0.01$ \\
Land use type & 6 & 38.09 & $<0.01$ \\
Forest type & 6 & 10.42 & $\mathrm{NS}$ \\
Grass height & 6 & 13.97 & $<0.05$ \\
Shrub height & 6 & 2.70 & $\mathrm{NS}$ \\
Land cover & 4 & 16.00 & $<0.01$ \\
Artificial structures & 8 & 100.39 & $<0.01$ \\
Water use & 6 & 22.93 & $<0.01$ \\
Pollutants & 6 & 58.38 & $<0.01$ \\
\hline NS: Not Significant & & &
\end{tabular}

Bukhangang and Namhangang, when habitat points in Bukhangang and Namhangang were grouped together $(\mathrm{p}<0.01)$ (Fig. 3).

Habitat variables such as site conditions, river width, bottom status, bankside vegetation, land use type, grass height, vegetation cover, artificial structures, water use and pollutants were significantly different among areas (Pearson $\chi^{2}$-test, $\chi^{2}=13.97-100.39, \mathrm{p}<0.05$ ). There were no differences in forest type and shrub height among areas (Table 3 ).

\section{DISCUSSION}

The Eurasian otter is a top predator in the aquatic food chain in most wetland ecosystems and its presence has been used to raise the profile of the animal and aid in its conservation (Wolters, 1994; Lans zki et al., 2009). Over the last five decades, this species has suffered severe declines in both habitat range and number of individuals but due to its secretive and nocturnal nature, these decreases have gone largely unnoticed (Mason and Macdonald, 1987).

A negative relationship between human disturbance (human population density, crop productivity, etc.) and otter inhabitation has been reported in most European countries (Madson and Macdonald, 1986). The European otter has been widely recorded in the Hangang river water system. However, factors that could prevent habitation by the Eurasian otter such as land use type, artificial structures, water use and pollutants have increased in intensity in South Korea in recent years.

Water systems provide important habitats for riparian wildlife such as the Eurasian otter. The main food items of the Eurasian otter are fishes and its habitat use is related with water, available shelters and food resources (Barbosa et al., 2001). To ensure conservation of the otters, efforts should be made to maintaine to high riparian cover and decrease obstacles in the water system (Medina, 1998).

Spraint abundance can be used as a broad indicator of the status of a population, provided sample sizes are large enough for statistical comparison. A high abundance of spraints indicates high revisitation rates (Medina-Vogel et al., 2003). researchers were able to assess the distribution and habitat conditions of the Eurasian otter by examining the characteristics of spraints and recording the sites at which they were collected as habitat points.

Although, researchers did not replicate this study in other water systems, the results do suggest that habitat conditions are the key determinants of the survival of Eurasian otter populations. Further studies are needed in similar water systems but the results can be used to aid effort to conserve this mammal and inform water management policies.

\section{CONCLUSION}

Most studies on otters have been conducted at relatively small scales and independently in space and time, often leading to the use of habitat variables too specific for large-scale conservation applications. The results underscore the need to study the Eurasian otter on a broader scale. A standardized and augmented index of land use would very useful for future broad-scale applications. 


\section{REFERENCES}

Alam, M.K., M.R. Mirza and O.E. Maughan, 1995. Constrains and opportunities in planning for the wise use of natural resources in developing countries: Examples of a hydropower project. Environ. Conserv., 22: 352-358.

Barbosa, A.M., R. Real, A.L. Marquez and M.A. Rendon, 2001. Spatial, environmental and human influences on the distribution of otter (Lutra lutra) in the Spanish provinces. Divers. Distrib., 7: 137-144.

Beja, P., 1996. An analysis of otter Lutra lutra predation on introduced American crayfish Procambarus clarkii in Iberian streams. J. Applied Ecol., 33: 1156-1170.

Collares-Perira, M.J., I.G. Cowx, F. Ribeiro, J.A. Rodrigues and L. Rogado, 2000. Threats imposed by water resource development schemes on the conservation of endangered fish species in the Guadiana River Basin in Portugal. Fish. Manage. Ecol., 7: 167-178.

Han, S.Y., 1987. Study on ecology of Eurasian otter Lutra lutra in Korea. Ph.D. Thesis, Kyungnam University, Changwon, Korea.

Jefferies, D.J., 1986. The value of otter Lutra lutra surveying using spraints: An analysis of its success and problems in Britain. Otter, 1: 25-32.

Jefferies, D.J., 1987. The Effects of Angling Interests on Otters, with Particular Reference to Disturbance. In: Angling and Wildlife in Fresh Waters: Proceedings of the Symposium Organized by the Scottish Freshwater Group and the British Ecological Society, University of Stirling, October 30, 1985, Mailland, P.S. and $\mathrm{K}$. Turner (Eds.). Institute of Terrestrial Ecology, Grange-Over-Sands, UK., pp: 23-30.

KWRC, 2002. The dam of Korea. Korea Water Resources Corporation, Gwacheon, Korea.

Kruuk, H. and J.W.H. Conroy, 1987. Surveying otter Lutra lutra populations: A discussion of problems with spraints. Biol. Conserv., 41: 179-183.

Lanszki, J., E. Orosz and L. Sugar, 2009. Metal levels in tissues of Eurasian otters (Lutra lutra) from Hungary: Variation with sex, age, condition and location. Chemosphere, 74: 741-743.

Lunnon, R.M. and J.D. Reynolds, 1991. Distribution of the Otter Lutra lutra in Ireland and its Value as an Indicator of Habitat Quality. In: Bioindicators and Environmental Management, Jeffrey, D.W. and B. Madden (Eds.). Academic Press, London, UK., ISBN: 9780123825902 , pp: 435-443.
Macdonald, S.M., C.F. Mason and Council of Europe, 1994. Status and Conservation Needs for the Otter (Lutra lutra) in the Western Palearctic. Council of Europe Press, Strasbourg, ISBN: 9789287124753, Pages: 54.

Madsen, A.B. and A. Prang, 2001. Habitat factors and the presence or absence of otters Lutra lutra in Denmark. Acta Theriol., 46: 171-179.

Madson, C.F. and S.M. Macdonald, 1986. Otters: Ecology and Conservation. Cambridge University Press, Cambridge, UK., ISBN: 9780521307161, Pages: 236.

Mason, C.F. and S.M. Macdonald, 1987. The use of spraints for surveying otter Lutra lutra populations: An evaluation. Biol. Conserv., 41: 167-177.

Medina, G., 1998. Seasonal variation and changes in the diet of southern river otter in different freshwater habitats in Chile. Acta Theriol., 43: 285-292.

Medina-Vogel, G., V.S. Kaufman, R. Monsalve and $\mathrm{V}$. Gomez, 2003. The influence of riparian vegetation, woody debris, stream morphology and human activity on the use of rivers by southern river otters Lontra provocax in Chile. Oryx, 37: 422-430.

Prenda, J. and C. Granadio-Lorencio, 1996. The relative influence of riparian habitat structure and fish availability on otter Lutra lutra L. sprainting activity in a small Mediterranean catchment. Biol. Conserv., 76: $9-15$.

Prigioni, C., L. Remonti, A. Balestrieri, S. Sgrosso, G. Priore, N. Mucci and E. Randi, 2006. Estimation of European otter (Lutra lutra) population size by fecal DNA typing in southern Italy. J. Mamm., 87: 855-858.

Robitaille, J.F. and S. Laurence, 2002. Otter, Lutra lutra, occurrence in Europe and in France in relation to landscape characteristics. Anim. Conserv., 5: $337-344$.

SMG, 2002. Research report of Hangang river ecosystem. Seoul Metropolitan Government, Seoul, Korea.

Sales-Luis, T., N.M. Pedroso and M. Santos-Reis, 2007. Prey availability and diet of the European otter (Lutra lutra) on a large reservoir and associated tributaries. Can. J. Zool., 85: 1125-1135.

Wolters, R., 1994. The otter and the European ecological network. Proceedings of the Seminar on the Conservation of the European Otter (Lutra lutra). June 7-11, 1994, Strasbourg, France, pp: 175-179. 